\title{
Diabetes is an Important Risk Factor for Metastasis in Non- Muscle-Invasive Bladder Cancer
}

\author{
Kutan Ozer ${ }^{1}$, Mustafa Ozan Horsanali ${ }^{1 *}$, Sacit Nuri Gorgel ${ }^{1}$, Emin Ozbek ${ }^{2}$
}

\begin{abstract}
Background: Epidemiological evidence indicates that individuals with diabetes mellitus (DM) may have a modestly increased risk of bladder cancer. In the present study, we aimed to show any association between DM and risk of metastasis in patients with non-muscle-invasive bladder cancer (NMIBC). Materials and Methods: We retrospectively analyzed 698 patients between January 2007 and December 2014 who were diagnosed with and underwent transurethral resection of bladder tumors (TUR-BT). Comparisons of means was conducted by independent samples $t$ test, and relations between categorical variables were investigated by non-parametric chisquare test. A p value of 0.05 was accepted as statistically significant in comparisons. Results: We analyzed 418 patients with non muscle invasive bladder cancer. 123 of whom were diabetic and 295 non-diabetic. In diabetic patients, 13 were $\mathrm{N} 1$ stage and $11 \mathrm{M} 1$ stage. When compared with non diabetic patients that was statistically significant $(p<0.001)$. TNM stages were more advanced in diabetic patients $(p<0.001)$, but concurrent $C I S(p=0.1)$ and squamous metaplasia did not significantly differ between diabetic and non-diabetic cases $(p=1)$. Conclusions: Diabetic patients with non-muscle-invasive bladder cancer may suffer metastases earlier than expected although they are non invasive. Therefore such patients must be followed-up carefully and early cystectomy decision may be necessary. Further prospective studies with more patients are needed to confirm these findings.
\end{abstract}

Keywords: Bladder cancer - diabetes mellitus - non-muscle-invasive - metastasis risk

Asian Pac J Cancer Prev, 17 (1), 105-108

\section{Introduction}

Urothelial carcinoma of the bladder is a common malignancy with an estimated 73,510 new cases and 14,880 deaths in 2012 in the United States. Compared to other places in the world, bladder cancer is considered to be a relatively common disease in Europe, North America, and Northern part of Africa (Siegel et al., 2012). Over $70 \%$ of the patients with bladder cancer are superficial bladder cancer at initial diagnosis, which would be managed with transurethral resection followed by intravesical chemotherapy (Bischoff et al., 2009). However, approximately $60 \%-70 \%$ of these cases will develop recurrent tumors, with $25 \%$ showing progression to a higher stage or grade (Schenk-Braat, 2005). The most important risk factor for bladder cancer is cigarette smoking, which is implicated in approximately $50 \%$ of the bladder cancer deaths in men and $30 \%$ in women (Zeegers et al., 2000).

Diabetes mellitus (DM) is a serious and growing health problem worldwide and is associated with severe acute and chronic complications that negatively affect both the quality of life and survival of affected individuals (Vigneri et al., 2009). In a meta-analysis study, epidemiological evidence indicates that individuals with diabetes mellitus may have a modestly increased risk of bladder cancer (Tripathi et al., 2002; Coughlin et al., 2004; Jee et al., 2005; Larsson et al., 2006).

The standard initial therapy for Ta and $\mathrm{T} 1$ papillary bladder tumors is a visually complete transurethral resection (TURBT) including a part of the underlying muscle (Brausi et al., 2002; Mariappan et al., 2010). A re-resection is advised if there is any doubt about the completeness of the initial TURBT, or if there was no muscle in the specimen (with the exception of Ta grade 1 tumors and primary CIS) within 2 to 6 weeks after the initial TURBT (Divrik et al., 2010). Because there is considerable risk for recurrence and/or progression of tumors after TURBT, perioperative and/or adjuvant intravesical instillation therapy is recommended (Sylvester et al., 2006). And, the standard of care for treatment of localized muscle-invasive bladder cancer (MIBC) is radical cystectomy (Rodel et al., 2002).

Different concentrations of hormones in individual organs, differentially expressed local factors, or paracrine growth factors may all influence the growth of malignant cells at particular sites (Plowman et al., 1981; Radinsky et al., 1991). Type 2 diabetes is characterized by Insulin 
resistance, inappropriate hepatic production of glucose and aberrant growth hormone production (Poulson et al., 1997). Diabetic patients have elevated insulin-like growth factor-1 (IGF-1) levels. The IGF axis is organized into IGFs, IGF binding proteins (IGFBPs), IGF proteases and membrane-associated receptors. The IGF axis plays an important role, through interacting with other hormonal axes, in determining cellular proliferation and apoptosis (Aaronson, 1991). IGF-1 stimulates cell growth by controlling cell cycle progression through G1 and play roles in carcinogenesis and metastasis (Stiles et al., 1979).

Local lymph node metastasis or distant metastasis is very rare in patients with non muscle invasive bladder cancer. In the literature there are limited case reports about early metastasis of non muscle invasive bladder cancer to thyroid gland, isolated bone metastasis and multiple bone metastasis. These is the first study in the literature that we showed association between diabetes mellitus and risk of metastasis in patients with non muscle invasive bladder cancer (NMIBC).

\section{Materials and Methods}

We retrospectively analyzed 698 patients between January 2007 and December 2014 who diagnosed bladder cancer and performed TUR-BT in Izmir Katip Celebi University Ataturk Training and Research Hospital Urology department. All patients with bladder cancer separated two groups as diabetic or non diabetic. All patient and tumor characteristic, TNM stage, CIS, squamous metaplasia and recurrens of tumor were analyzed. Incomplete TUR-BT, non-urothelial cancers and recurrent non-muscle invasive bladder cancers were excluded from study. Remained 418 patients were analyzed.

The clinical staging of the 2002 TNM classification. Ta tumor was accepted as lower stage bladder carcinoma. Ta and T1 tumors were accepted as non muscle invasive bladder cancer. Also, pathological grading adopted by the 2004 World Health Organization grading system were used.

All statistical analysis were performed by using SPSS17.0 statistical package program. The descriptive statistics we represented as frequencies and percentages for categorical variables and means and standard deviations for continuous variables. The comparisons of the means were examined by independent samples $t$ test, and the relations between categorical variables were investigated by non-parametric chi-square test. A p value 0.05 was accepted statistically significant in comparisons.

\section{Results}

We retrospectively analyzed 418 patients with non muscle invasive bladder cancer. 123 patients were diabetic and 295 of were non-diabetic. Mean age of all patients were $66.2 \pm 12.1$ years old. $365(87 \%)$ of male and 53 $(13 \%)$ of female patients.

Tumor characteristics, TNM stages, grades, CIS and squamous metaplasia characteristics for both diabetic and non-diabetic patients were shown in Table 1 and 2 .
Table 1.Tumor Characteristics for Groups

\begin{tabular}{lrrrc}
\hline & Age & $\begin{array}{c}\text { Tumor } \\
\text { Size }\end{array}$ & $\begin{array}{c}\text { Turmor } \\
\text { Burden }\end{array}$ & $\begin{array}{c}\text { Relaps } \\
\text { Frequency }\end{array}$ \\
\hline Diabetic Patients & 67.4 & 3.2 & 2.01 & 1.4 \\
Non-Diabeti c Patien & 63.9 & 3.3 & 1.95 & 0.8 \\
\hline
\end{tabular}

Table 2. TNM Staging. Grade. CIS and Squamous Metaplasia Characteristics for Groups

\begin{tabular}{|c|c|c|c|}
\hline & $\begin{array}{l}\text { Diabetic } \\
\text { Patients }\end{array}$ & $\begin{array}{c}\text { Non-Diabetic } \\
\text { Patients }\end{array}$ & P Value \\
\hline \multicolumn{3}{|l|}{ T Stage } & $<0.001$ \\
\hline $\mathrm{Ta}$ & $60(48.8 \%)$ & $212(71.9 \%)$ & \\
\hline $\mathrm{T} 1$ & $63(51.2 \%)$ & $83(28.1 \%)$ & \\
\hline \multicolumn{3}{|l|}{ N Stages } & 0.009 \\
\hline No & $113(91.9 \%)$ & $289(98 \%)$ & \\
\hline N1 & $10(8.1 \%)$ & $6(2 \%)$ & \\
\hline \multicolumn{3}{|l|}{ M Stages } & $<0.001$ \\
\hline M0 & $112(91.1 \%)$ & $294(99.7 \%)$ & \\
\hline M1 & $11(8.9 \%)$ & $1(0.3 \%)$ & \\
\hline \multicolumn{3}{|l|}{ Grade } & $<0.001$ \\
\hline G1 & $28(22.8 \%)$ & $114(38.6 \%)$ & \\
\hline G2 & $40(32.5 \%)$ & $109(36.9 \%)$ & \\
\hline G3 & $55(44.7 \%)$ & $72(24.4 \%)$ & \\
\hline \multicolumn{3}{|l|}{ Cis } & 0.117 \\
\hline Yes & $9(7.3 \%)$ & $11(3.7 \%)$ & \\
\hline No & $114(92.7 \%)$ & $284(96.3 \%)$ & \\
\hline \multicolumn{3}{|c|}{ Squamous Metaplasia } & 1 \\
\hline Yes & $2(1.6 \%)$ & $5(1.7 \%)$ & \\
\hline No & $121(98.4 \%)$ & $290(98.3 \%$ & \\
\hline
\end{tabular}

There was statistically significance between two groups in TNM stages, grades and relapse frequency. Although all patients are NMIBC, $10(8.1 \%)$ patients were N1 stage and $11(8.9 \%)$ patients were M1 stage in diabetic patients and that was statistically significant. For all patients, there was statistically significance for relapse frequency and that was higher in diabetic patients than non-diabetic patients $(\mathrm{p}=0.001)$. T, $\mathrm{N}$ and $\mathrm{M}$ stages were more advance in diabetic patients $(p<0.001)$, but concurrent CIS ( $\mathrm{p}=0.1$ ) and squamous metaplasia between diabetic and non-diabetic patients were not significant $(\mathrm{p}=1)$.

\section{Discussion}

The result of the present study show that diabetic patients with NMIBC present more early distant metastasis than non diabetic patients with NMIBC. Also diabetic patients have more advanced stage, grade and relapse frequency than non diabetic patients. Previous studies in literature show that diabetes mellitus is independent risk factor for recurrence free survival and progression free survival for the diabetic patients with NMIBC (Hwang et al., 2011).

The mechanism by which DM contributes towards bladder cancer remains unknown. One suggestion is that chronic exposure to hyperinsulinemia or hyperglycemia induces tumor cell proliferation and metastasis, that increased insulin-like growth factor (IGF)-1 in diabetic patients stimulates cellular proliferation and inhibits 
apoptosis (Attia et al., 1999; Richardson et al., 2005). Another possible mechanism is structural changes in urothelium due to diabetic nephropathy. Cadherin expression and degradation of glycFFosaminoglycans in bladder tissue is affected by DM, this could explain the poor prognosis of patient with DM. Reduced expression of E-cadherin is associated with poor outcomes in bladder cancer patients and has been shown to be correlated with increased tumor invasion (Lipponen et al., 1995; Chen et al., 2000). Metformin has been widely used oral anti diabetic agent among diabetic patients. Although diabetes play role to develop some kind of cancers, some studies show that metformin significantly inhibited the proliferation and colony formation of 5637 and T24 cells in vitro; specifically, metformin induced an apparent cell cycle arrest in G0/G1 phases, accompanied by a strong decrease of cyclin D1, cyclin-dependent kinase 4 (CDK4), $\mathrm{E} 2 \mathrm{~F} 1$ and an increase of $\mathrm{p} 21$. Further experiments revealed that metformin activated AMP-activated protein kinase (AMPK) and suppressed mammalian target of rapamycin (mTOR), the central regulator of protein synthesis and cell growth. Moreover, daily treatment of metformin led to a substantial inhibition of tumor growth in a xenograft model with concomitant decrease in the expression of proliferating cell nuclear antigen (PCNA), cyclin D1 and p-mTOR. So these effect of metformin can be protect patients against bladder cancer development (Zhou et al., 2001; Boyle et al., 2010; Zhang et al., 2013).

Mamatani et al reported their study that compared bladder cancer risk in the metformin users relative to sulfonylureas users, there was likewise no pattern of decreasing relative risk of bladder cancer associated with metformin use with increasing duration of metformin therapy (metformin vs. sulfonylurea therapy: 3 to, 4 years of use: HR 0.57 [95\% CI 0.25-1.34]; 4 to, 5 years of use: 0.93 [0.30-2.85] and no association with risk of bladder cancer by the duration of metformin relative to sulfonylurea use, or metformin, or sulfonylurea use alone (Mamtani et al., 2014).

Reiken at all found that patients with NMIBC and DM who did not take metformin had a significantly shorter recurrence-free and progression-free survival than their counterparts without DM or those with DM taking metformin. Furthermore, DM without metformin use was associated with a higher risk of disease recurrence and progression, whereas DM with metformin use was independently associated with a lower risk of recurrence (Rieken et al., 2013).

Turati et al showed that diabetics having about twofold excess risk in bladder cancer as compared with nondiabetics and the excess risk of bladder cancer increases with duration of diabetes (Turati et al., 2015).

45,000 Swedish men followed for over 9 years, of whom 414 developed bladder cancer, found bladder cancer incidence to be 1.2 times higher in men reporting a history of diabetes, but this was not statistically significant (Larsson et al., 2008).

However, in the study of MacKenzie et al. (2011) found that risk of bladder cancer was elevated among those with a history of diabetes patients, in particular, those taking oral hypoglycemics or insulin. Additionally, the association increased with duration of diabetes (MacKenzie et al., 2011).

Matrix metalloproteinases (MMPs) are required in biological functions, such as cell proliferation, differentiation, apoptosis, immune function, tissue healing, and angiogenesis. Therefore, they are also involved in multiple pathological conditions (Amalinei et al., 2010). MMPs certainly play a large part in cancer progression and metastatic invasion, since they can promote cancer growth, development and metastatic diffusion, particularly in the 'pre-metastatic niche', the site where the early changes occur in cancer cells, in order to start metastatic diffusion (Rucci et al., 2011). Based on these studies, diabetes may lead to early metastases in NMIBC via MMPs.

A limitation of our study is our inability to record glycemic parameters because of the retrospective design of study. We did not have information on glucose levels or other markers of glucose control because of the data record system of our hospital. We were unable to assess whether the increased risk of metastasis found among those receiving oral anti-diabetic drugs or insulin was due to the medication, or if the medication was a marker for more severe diabetes. Additionally, we did not have detailed drug information, which precluded our ability to examine dose or specific type of therapy (e.g., for oral agents).

As shown in the previous previous studies, diabetes can lead to bladder cancer, but we think that diabetes either lead to develop bladder cancer or metastasis earlier than expected. So we suggest close follow-up for the diabetic patients with NMIBC than non-diabetic patients. And also, early cystectomy decision may done for this patients earlier than expected. Further prospective, multi center studies are needed to confirm our suggestions.

\section{Acknowledgements}

Special thanks to Tolga Cevizci for statistical analyses.

\section{References}

Aaronson S (1991). Growth factors and cancer. Sci, 254, 114653.

Amalinei C, Caruntu ID, Giusca SE, et al (2010). Matrix metalloproteinases involvement in pathologic conditions. Rom J Morphol Embryol, 51, 215-28.

Attia N, Caprio S, Jones TW, et al (1999). Changes in free insulin-like growth factor-1 and leptin concentrations during acute metabolic decompensation in insulin withdrawn patients with type 1 diabetes. J Clin Endocrinol Metab, 84, 2324-8.

Bischoff CJ, Clark PE (2009). Bladder cancer. Curr Opin Oncol, 21, 272-7.

Boyle JG, Salt IP, McKay GA (2010). Metformin action on AMPactivated protein kinase, A translational research approach to understanding a potential new therapeutic target. Diabet Med, 27, 1097-106.

Brausi M, Collette L, Kurth K, et al (2002). EORTC genitourinary tract cancer collaborative group. variability in the recurrence rate at first follow-up cystoscopy after TUR in stage Ta T1 transitional cell carcinoma of the bladder, a combined analysis of seven EORTC studies. Eur Urol, 41, 523-31. 


\section{Kutan Ozer et al}

Chen HC, Chen CA, Guh JY, et al (2000). Altering expression of alpha3beta1 integrin on podocytes of human and rats with diabetes. Life Sci, 67, 2345-53.

Coughlin SS, Calle EE, Teras LR, et al (2004). Diabetes mellitus as a predictor of cancer mortality in a large cohort of US adults. Am J Epidemiol, 159, 1160-7.

Divrik RT, Sahin AF, Yildirim U, et al (2010). Impact of routine second transurethral resection on the long-term outcome of patients with newly diagnosed pT1 urothelial carcinoma with respect to recurrence, progression rate, and diseasespecific survival, a prospective randomised clinical trial. Eur Urol, 58, 185-90.

Hong JH (2015). Early isolated bone metastases without local recurrence in non-muscle invasive bladder cancer. Int J Surg Case Rep, 10, 41-4.

Hwang EC, Kim YJ, Hwang IS, et al (2011). Impact of diabetes mellitus on recurrence and progression in patients with nonmuscle invasive bladder carcinoma, A retrospective cohort study. Int J Urol, 18, 769-76.

Jee SH, Ohrr H, Sull JW, et al (2005). Fastingserum glucose level and cancer risk in Korean men and women. JAMA, 293, 194-202.

Larsson SC, Orsini N, Brismar K, et al (2006). Diabetes mellitus and risk of bladder cancer, a meta-analysis. Diabetologia, 49, 2819-23.

Larsson SC (2008). Diabetes mellitus, body size and bladder cancer risk in a prospective study of Swedish men. Eur $J$ Cancer, 44, 2655-60.

Lipponen PK, Eskelinen MJ (1995). Reduced expression of E-cadherin is related to invasive disease and frequent recurrence in bladder cancer. J Cancer Res Clin Oncol, 121, 303-8

MacKenzie T, Zens MS, Ferrara A, et al (2011). Diabetes and risk of bladder cancer, evidence from a case-control study in New England. Cancer, 117, 1552-6.

Mamtani R, Pfanzelter N, Haynes K, et al (2014). Incidence of bladder cancer in patients with type 2 diabetes treated with metformin or sulfonylureas. Diabetes Care, 37, 1910-7.

Mariappan P, Zachou A, Grigor KM (2010). Detrusor muscle in the first, apparently complete transurethral resection of bladder tumour specimen is a surrogate marker of resection quality, predicts risk of early recurrence, and is dependent on operator experience. Eur Urol, 57, 843-9.

Plowman GD, Green JM, McDonald VL, et al (1981). The amphiregulin gene encodes a novel epidermal growth factor-related protein with tumor-inhibitory activity. $\mathrm{Mol}$ Cell Biol, 10, 1969-81.

Poulson J (1997). The management of diabetes in patients with advanced cancer. J Pain Symptom Manage, 13, 339-34.

Radinsky R (1991). Growth factors and their receptors in metastasis. Semin Cancer Biol, 2, 169-77.

Richardson LC, Pollack LA (2005). Therapy insight, influence of type 2 diabetes on the development, treatment and outcomes of cancer. Nat Clin Pract Oncol, 2, 48-53.

Rieken M, Xylinas E, Kluth L, et al (2013). Association of diabetes mellitus and metformin use with oncological outcomes of patients with non-muscle invasive bladder cancer. BJU Int, 112, 1105-12.

Rodel C, Grabenbauer GG, Kuhn R, et al (2002). Combinedmodality treatment and selective organ preservation in invasive bladder cancer, long-term results. J Clin Oncol, 20, 3061-71.

Rucci N, Sanita P, Angelucci A (2011). Roles of metalloproteases in metastatic niche. Curr Mol Med, 11, 609-22.

Sasaki Y1, Oi H, Oyama T, et al (2013). Non-muscle invasive bladder cancer with multiple bone metastasis without local invasion, a case report. Hinyokika Kiyo, 59, 669-72.
Schenk-Braat, EA, Bangma, CH, (2005). Immunotherapy for superficial bladder cancer. Cancer Immunol Immunother, 54, 414-423.

Siegel R, Naishadham D, Jemal A (2012). Cancer statistics, 2012. CA Cancer J Clin, 62, 10-29.

Stiles CD, Capone GT, Scher CD, et al (1979). Dual control of cell growth by somatomedins and platelet-derived growth factor. Proc Natl Acad Sci USA, 76, 1279-83.

Sylvester RJ, van der Meijden AP, Oosterlinck W, et al (2006). Predicting recurrence and progression in individual patients with stage TaT 1 bladder cancer using EORTC risk tables, a combined analysis of 2596 patients from seven EORTC trials. Eur Urol, 49, 466-77.

Tripathi A, Folsom AR, Anderson KE (2002). Risk factors for urinary bladder carcinoma in postmenopausal women. the iowa women's health study. Cancer, 95, 2316-23.

Tuncer M, Faydaci G, Altin G, et al (2014). Metastasis of nonmuscle-invasive bladder cancer into the thyroid gland, a literature review accompanied by a rare case. Korean $J$ Urol, 55, 222-5.

Turati F, Polesel J, Di Maso M, et al (2015). Diabetes mellitus and the risk of bladder cancer, an Italian case-control study. Br J Cancer, 1-4.

Vigneri P, Frasca F, Sciacca L, et al (2009). Diabetes and cancer. Endocr Relat Cancer, 16, 1103-23.

Zeegers MP, Tan FE, Dorant E, et al (2000). The impact of characteristics of cigarette smoking on urinary tract cancer risk, a meta-analysis of epidemiologic studies. Cancer, $\mathbf{8 9}$, 630-9

Zhang T, Guo P, Zhang Y, et al (2013). The antidiabetic drug metformin inhibits the proliferation of bladder cancer cells in Vitro and in Vivo. Int J Mol Sci, 14, 24603-18.

Zhou G, Myers R, Li Y, et al (2001). Role of AMP-activated protein kinase in mechanism of metforminaction. $J$ Clin Invest, 108, 1167-74. 